\title{
Maternal and umbilical cord blood polymorphonuclear leukocytes showed moderate oxidative burst at phagocytosis of Gardnerella vaginalis
}

\author{
Anushia Swaminathan ${ }^{1}$, Nor Haslinda Abd Aziz², Najiah Ajlaa Ayub ${ }^{3}$, Kon-Ken Wong ${ }^{4}$ and Fook-Choe Cheah ${ }^{1 *}$
}

\begin{abstract}
Objective: Pregnant women with bacterial vaginosis due to Gardnerella vaginalis (GV) infection presents with a wideranging disease symptomatology. We speculate this may be due to interaction that varies between host immune response and the pathogen. We studied the oxidative burst in polymorphonuclear leukocytes (PMNL)s from maternal blood (MB) and cord blood (CB) upon phagocytosis of GV and compared against E. coli and Group B Streptococcus (GBS).

Results: The PHAGOBURST ${ }^{\mathrm{TM}}$ assay detects fluorescence from oxidized dihydrorhodamine during oxidative burst. The average percentage of PMNL showing oxidative burst was almost two-fold greater with GBS (99.5\%) and E. coli (98.2\%) than GV (56.9\%) ( $p<0.01$ ) in MB, but a similar proportion of PMNL with burst activity was seen in CB (84.7\%). The mean fluorescence intensity (MFI) of oxidative burst in MB PMNL with GV was lower compared to E. coli but comparable to GBS. The MFI of CB PMNL (1580 \pm 245.8$)$ was significantly higher than MB PMNL (1198 \pm 262.1$)$ with GV, p $=0.031$. The live-cell imaging showed neutrophil oxidative burst upon phagocytosis of $\mathrm{GV}$ produces hypochlorous acid (HOCl). Overall, the HOCL-mediated microbicidal activity against GV is more variable and less robust than E. coli and GBS, especially in maternal than CB PMNL.
\end{abstract}

Keywords: Bacterial vaginosis, Dihydrorhodamine, E. coli, Fluorescence, Group B Streptococcus, Hypochlorous acid, Immune response, Neutrophil, Newborn infant, Reactive oxygen species

\section{Introduction}

Gardnerella vaginalis (GV) is a vaginal commensal commonly isolated in women of reproductive age. It is also recognised as a prevalent organism responsible for bacterial vaginosis $(\mathrm{BV})[1]$. The effects of $\mathrm{BV}$ are variable; from being asymptomatic to complicated pregnancies with fetal growth restriction or preterm birth $[2,3]$. The host immune response to antenatal infection with GV needs

\footnotetext{
*Correspondence: cheahfc@ppukm.ukm.edu.my

1 Department of Paediatrics, Faculty of Medicine, Universiti Kebangsaan

Malaysia, Jalan Yaacob Latif, 56000 Kuala Lumpur, Malaysia

Full list of author information is available at the end of the article
}

further elucidation. Studies on the pathogenicity of GV are largely on epithelial cells in vitro [4-6] while information on host-pathogen interaction involving blood leukocytes is very limited. Recently, it was demonstrated that neutrophils from peripheral blood of healthy adults and amniotic fluid rapidly phagocytosed GV [7]. However, very few have studied the oxidative burst of PMNL during phagocytosis to eradicate GV. At infection sites, PMNLs are the major cells recruited and reactive oxygen species (ROS) are produced in bacterial killing. A major pathway involved is the NADPH oxidase mediated production of superoxide, hydrogen peroxide and hypochlorous acid 
( $\mathrm{HOCl})$, the most potent antimicrobial oxidant which is myeloperoxidase (MPO) derived [8-10].

Our study sought if variability in the BV spectrum of disease among pregnant women and neonatal outcomes could be attributed to the innate host immune response during phagocytosis. We further speculate that antenatal exposure to GV may result in maternal protective immune response to the fetus, creating a difference between maternal and cord blood phagocytic responses. Our results showed a variable and modest oxidative burst especially when PMNL from maternal blood (MB) phagocytosed GV compared to $E$. coli and GBS. The livecell imaging further showed that this is $\mathrm{HOCl}$-mediated.

\section{Main text \\ Methods \\ Subjects}

Peripheral blood samples were obtained after written informed consent from 10 healthy pregnant women during antenatal clinic visits or pre-delivery at the Universiti Kebangsaan Malaysia (UKM) Medical Centre, Kuala Lumpur. The eight cord blood (CB) samples were drawn from the umbilical cord arteries after delivery of the placenta. This study was approved by the Research Ethics Committee of UKM. The clinical characteristics of the subjects are in Table 1 . The neutrophil preparation and live-cell imaging were carried out at the Centre for Free Radical Research, University of Otago at Christchurch, New Zealand. A purified sample of neutrophils from the blood of a healthy laboratory staff volunteer collected for another unrelated study was used.

\section{Preparation of bacteria cultures and opsonisation}

The GV, ATCC ${ }^{\circledR} 14018^{\mathrm{TM}}$ was used as the reference strain. Comparative studies utilized GBS, ATCC ${ }^{\circledR} 13813^{\mathrm{TM}}$ and lyophilized pre-opsonised E. coli, provided as control in the PHAGOBURST ${ }^{\mathrm{TM}}$ kit. Columbia Blood Agar with sheep blood medium (Thermo Scientific, Melaka, Malaysia) was used for subculturing of GV and GBS, and plates were incubated in $5 \% \mathrm{CO}_{2}$ at $37{ }^{\circ} \mathrm{C}$. To prepare the bacterial suspensions, freshly streaked colonies were inoculated into Mueller Hinton Broth (MHB) (Thermo Scientific, Melaka, Malaysia), placed on a shaker and incubated at $37^{\circ} \mathrm{C}$ overnight $(24 \mathrm{~h})$. The concentrations of GV and GBS suspension were adjusted to $1-2 \times 10^{9}$ / $\mathrm{mL}$ respectively, using the SmartSpec ${ }^{\text {TM }} 3000$ Spectrophotometer (Bio-Rad Laboratories, Hercules, CA). The opsonisation of GV and GBS utilised the serum from the corresponding $\mathrm{MB}$ or $\mathrm{CB}$ samples.

\section{Oxidative burst assay}

A separate aliquot of the blood sample from the MB or $\mathrm{CB}$ was placed in plain tubes for serum separation which were then used for opsonisation of GV and GBS following a previously published method [11]. Briefly, whole blood was centrifuged at $25^{\circ} \mathrm{C}$ at $4000 \mathrm{rpm}$ for $20 \mathrm{~min}$. The serum was transferred into glass tubes and opsonisation of bacteria was carried out at a ratio of 1:10 of bacterial suspension to serum ( $\mathrm{vol} / \mathrm{vol})$. The tubes were placed on a rotator and incubated at $37^{\circ} \mathrm{C}$ for $30 \mathrm{~min}$.

A $100 \mu \mathrm{L}$ of heparinized blood was aliquoted into $5 \mathrm{~mL}$ tubes placed on ice $\left(0{ }^{\circ} \mathrm{C}\right)$ for $10 \mathrm{~min}$. Experiments were carried out according to the manufacturer's instructions of PHAGOBURST ${ }^{\mathrm{TM}}$ (Glycotope $\mathrm{GmbH}$, Heidelberg, Germany): samples of whole blood were stimulated with either $20 \mu \mathrm{L}$ of Phorbol 12-Myristate 13-Acetate (PMA) as high stimulus, $\mathrm{N}$-formyl-MetLeuPhe (fMLP) as low stimulus, pre-opsonised E. coli bacteria $\left(1-2 \times 10^{9} / \mathrm{mL}\right)$ as particulate/bacterial stimulus as positive controls. For comparison, the opsonised GV and GBS (each at approximately $1.5 \times 10^{9} / \mathrm{mL}$ ) prepared as above, were used as test stimuli. Samples were incubated in a water bath for

Table 1 Clinical characteristics of the mothers $(n=10)$ and neonates $(n=8)$

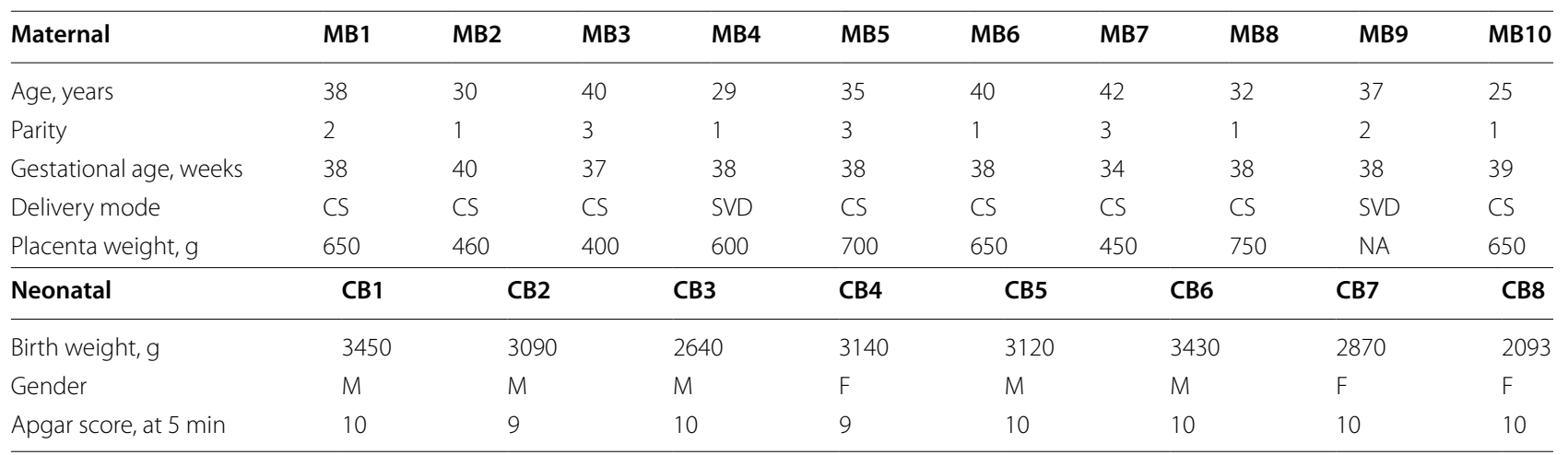

Only MB1-6 are maternal blood samples paired with the corresponding cord blood samples, CB1-6

$N A$ not available; $M$ male; $F$ female; $C S$ caesarean section; SVD spontaneous vaginal delivery 
$10 \mathrm{~min}$ at $37{ }^{\circ} \mathrm{C}$. The samples were then assayed using BD FACSVerse ${ }^{\mathrm{TM}}$ Flow Cytometer (BD Biosciences, San Jose, CA). Data were analysed with BD FACSuite ${ }^{\mathrm{TM}}$ software (BD Biosciences, San Jose, $\mathrm{CA}$ ) and the values were reported as the percentage of cells exhibiting fluorescent oxidised DHR of the total events and the average intensity of oxidative burst was estimated by the mean fluorescence intensity (MFI) per cell.

\section{Neutrophil preparation and live-cell imaging}

Neutrophils were prepared by dextran sedimentation, Ficoll-Paque (GE Healthcare, Auckland, New Zealand) centrifugation and lysis of contaminating red blood cells [12]. The neutrophil pellet is finally re-suspended in Hank's buffered salt solution. One mM of Reagent R19-S (FutureChem Co., Seoul, Republic of Korea) stock solutions in acetonitrile were prepared fresh. R19-S reacts with $\mathrm{HOCl}$ to give the fluorescent product, R19 [13]. The neutrophils were placed in a $35-\mathrm{mm}$ glass bottomed dish, R19-S and reagents were added 10 min prior to stimulation with opsonised GV [14]. Live-cell fluorescence emission was used to observe $\mathrm{HOCl}$ production. An Olympus IX-81 live-cell inverted microscope attached with an XM10 monochrome fluorescence camera and Cell R software (Olympus Soft Imaging Solutions, Munster, Germany) was used to capture time-lapse images [14].

\section{Statistical analysis}

Mann Whitney-U test was used to analyse the comparison between $\mathrm{MB}$ and $\mathrm{CB}$ for the percentage of cells with oxidative burst. Independent $t$ test was used to analyse the MFI values. Comparisons between the paired MB and $\mathrm{CB}$ for percentage of oxidative burst used the Wilcoxon test whereas MFI values were analysed with paired $\mathrm{t}$ test. Data are presented as mean \pm SEM for parametric data, median (IQR) for non-parametric data. A p value less than 0.05 was considered statistically significant. The statistical software used was GraphPad Prism Version 8.0.2 (GraphPad Software, San Diego, CA).

\section{Results}

\section{Clinical characteristics of subjects}

The mean age of the women was 35 years, gestation of 38 weeks and all but two delivered by caesarean section (Table 1). All the infants had normal Apgar scores (Table 1). Their mean birth weight was 2979 g. Out of the $10 \mathrm{MB}$ samples, there were only six MB-CB pairs: MB-CB1-6.

\section{Oxidative burst in leukocytes}

The selected leukocyte population studied was PMNL based on the scatter properties in flow cytometry (Fig. 1a). Overall, oxidative burst intensity was modest in PMNL when stimulated by GV in comparison to the more robust response to PMA (Fig. 1b). Nearly all PMNL in MB showed oxidative burst when stimulated by GBS (99.5\%) and E. coli (98.2\%) as compared with GV (56.9\%). There was also a wider range in the percentage of PMNL with oxidative burst at phagocytosis of GV (maximum, 99.4\% to minimum, 13.4\%) (Fig. 1c). The proportion of PMNL in CB showing oxidative burst when challenged with the three bacterial species, was similar with E. coli (97.7\%) and GBS (97.5\%) but lower with GV (84.7\%) but the difference was not statistically significant. Even so, the PMNL in $\mathrm{CB}$, as in the case with $\mathrm{MB}$, showed greater variability with oxidative burst to GV, ranging between 35.3 and 99.9\% (Fig. 1c). Stimulation by E. coli and GBS consistently showed PMNL generating oxidative bursts equivalent to PMA as a stimulus, but not with exposure to GV. However, activation by GV showed greater oxidative burst than fMLP as stimulus, in both $\mathrm{MB}$ and $\mathrm{CB}$ (Fig. 1d). With regards to the intensity of oxidative burst, MB PMNL when stimulated by GV had significantly lower MFI $(1026 \pm 176)$ than with E. coli, MFI $(1717 \pm 220.6)$. This was also seen in CB, although the difference was not statistically significant (Fig. 1e). Overall, the oxidative burst intensity in PMNL from $\mathrm{MB}$ or $\mathrm{CB}$ was highest with PMA and $E$. coli stimulation, moderate with GV and GBS, and was lowest with fMLP (Fig. 1f).

We further looked into the six paired MB and CB samples. The PMNL showing oxidative bursts were not different between $\mathrm{MB}$ and $\mathrm{CB}$ : E. coli, $99.1 \%$ vs. 97.9\%; GBS, $99.5 \%$ vs $98.3 \%$ and GV, $83.2 \%$ vs $95.2 \%$, respectively. However, the oxidative burst intensity in PMNL reacting to $\mathrm{GV}$ was significantly higher in $\mathrm{CB}$, MFI $(1580 \pm 245.8)$ than MB, MFI $(1198 \pm 262.1) ; \mathrm{p}=0.031$. There was no difference in the intensity in PMNL between $\mathrm{MB}$ and $\mathrm{CB}$ when stimulated by E. coli or GBS.

\section{Live cell-imaging of phagocytosis and oxidative burst}

The use of live imaging captured the phagocytosis of GV by neutrophils and fluorescence emission when $\mathrm{HOCl}$ is generated in the phagosome. A faint red fluorescence was seen in the beginning ( $0 \mathrm{~s})$ (Fig. 2a), with an increasing fluorescence intensity observed over time (10 and $20 \mathrm{~s}$ ) (Fig. 2b, c respectively). The number of neutrophils producing red fluorescence is also seen to increase but at a heterogeneous speed, followed by lowering in the intensity with quenching over time. An additional movie file shows these in more detail (see Additional file 1).

\section{Discussion}

A seminal study by Easmon et al. reporting how peripheral blood neutrophils of healthy adults phagocytosed and killed GV was published almost 4 decades ago. [15] Although GV is the second most common organism 
a

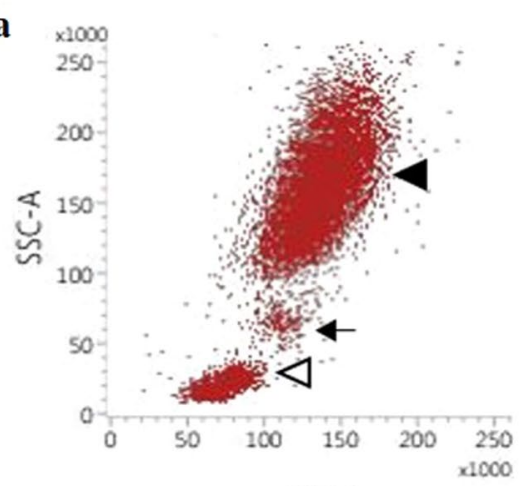

FSC-A

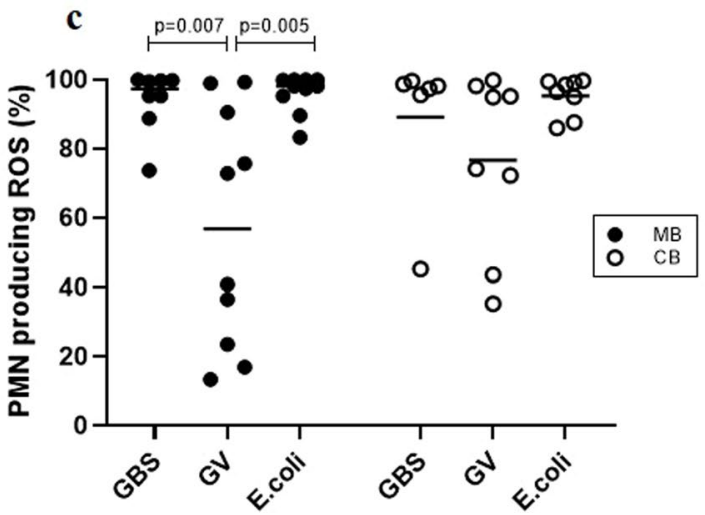

e

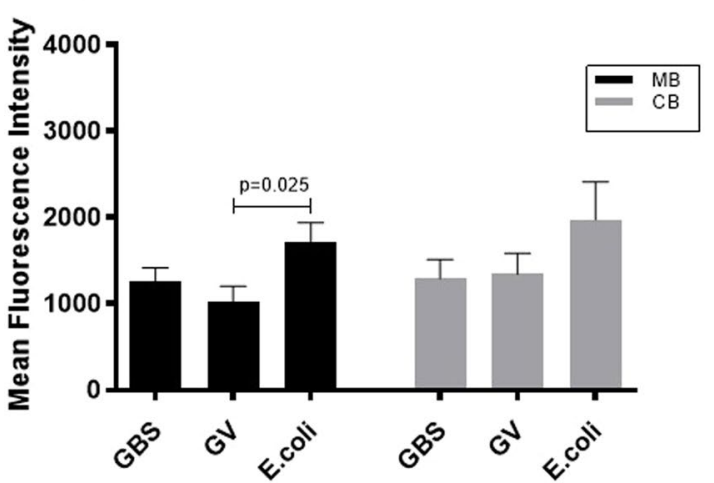

b

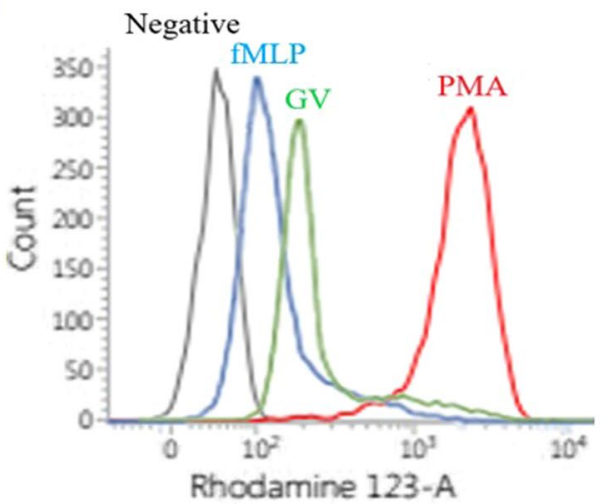

d

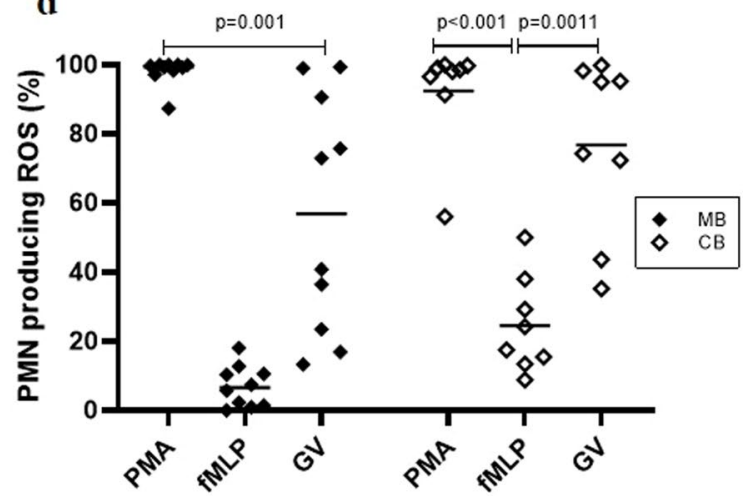

f

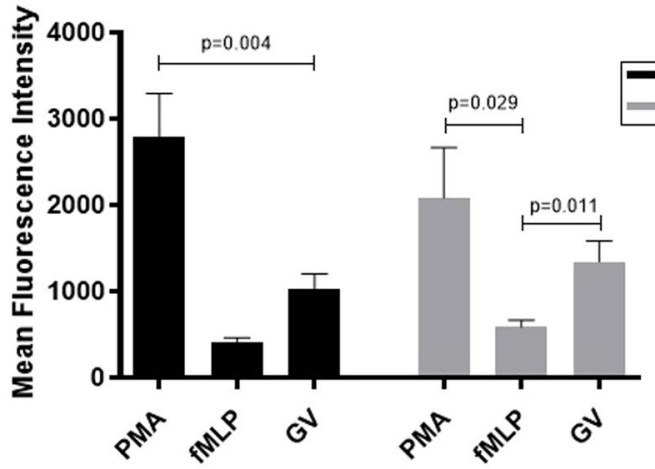

Fig. 1 Oxidative burst responses in polymorphonuclear leukocytes (PMNLS) from maternal blood (MB) and cord blood (CB) with various stimuli. a Forward and side light scatter showing the leukocyte population in whole blood; black arrowhead = PMNLs, black arrow = Monocytes, open arrowhead = Lymphocytes. $\mathbf{b}$ Fluorescence detection by the DHR-based oxidative burst assay on flow cytometry when PMNL are stimulated by PMA, fMLP and GV.The increased fluorescence production in PMNL when stimulated by PMA results in a significant right shift in the histogram. In comparison, fluorescence intensity is modest when the PMNL is stimulated by GV. c The proportion (median, IQR) of activated PMNL showing oxidative burst from MB and CB in response to the three bacteria; GBS: MB, 99.5\% (95.4-99.9\%), CB, 97.5\% (88.9-98.8\%); GV: MB, 56.9\% (21.9-92.8\%), CB, 84.7\% (50.8-97.5\%) and E. coli: MB, 98.2\% (93.9-100.0\%), CB, 97.7\% (89.6-99.4\%). The PMNL shows more variability in generating oxidative burst in both $M B$ and $C B$ with $G V$ stimulus. This difference is more marked in the MB than CB. $\mathbf{d}$ The percentage (median, IQR) of activated PMNL with oxidative burst in MB and CB when stimulated by PMA, fMLP and GV shows the response was highest with PMA: MB, 99.5\% (98.1-100\%), CB, 98.4\% (92.7-99.6\%), followed by GV: MB, 56.9\% (21.9-92.8\%), CB, 84.7\% (50.8-97.5\%) and fMLP: MB, 6.6\% (1.3-11.2\%), CB, 20.9\% (14.0-35.9\%). e Intensity of oxidative burst, measured as mean fluorescence intensity (mean \pm SEM) is highest with E. coli: MB (1717 \pm 220.6$), C B(1971 \pm 441.2)$ than GBS: MB (1252 \pm 163.4), CB (1293 \pm 217.2$)$ or GV: MB (1026 \pm 176$), C B(1340 \pm 243.5)$. f Intensity of oxidative burst is moderate with GV: MB (1026 \pm 176$)$, CB (1340 \pm 243.5$)$ in both MB and CB, compared against the high stimulus, PMA: MB (2784 \pm 509.2$), C B(2081 \pm 584.7)$ and low stimulus, fMLP: MB (400.9 \pm 60.47$), C B(585.5 \pm 78.4)$. ( $M B, n=10 ; C B, n=8$; with $G B S, M B$ and $C B, n=7$ each) 


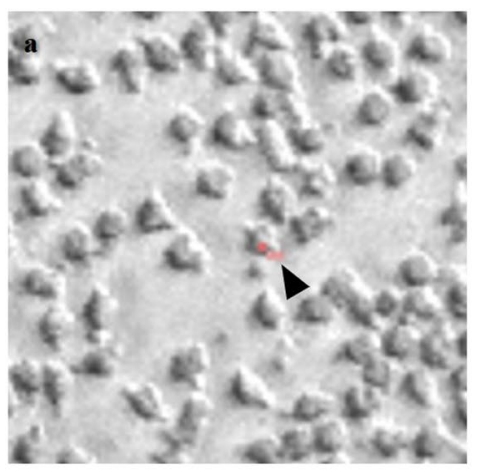

$0 \mathrm{sec}$

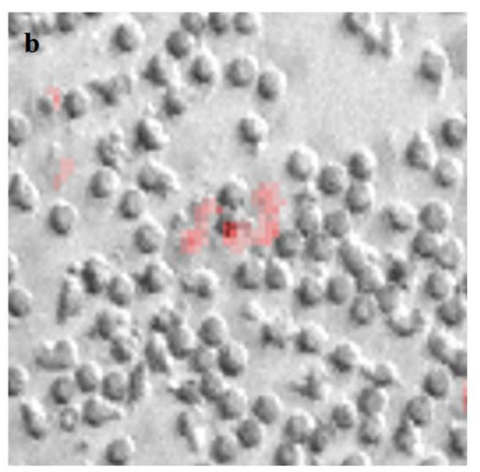

$10 \mathrm{sec}$

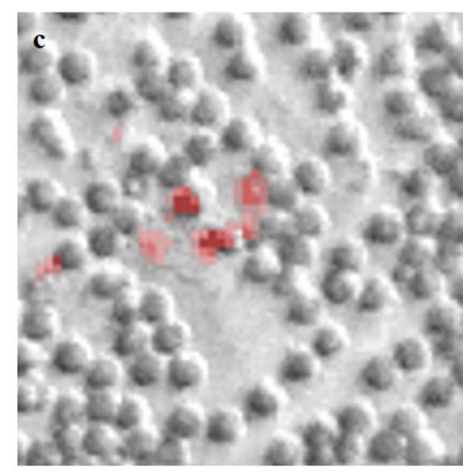

$20 \mathrm{sec}$

Fig. 2 The rhodamine-based probe R19-S reacts with $\mathrm{HOCl}$ to yield fluorescent R19, in red (13). a The initial phase of oxidative burst appearing as faint red fluorescence in an activated neutrophil with pseudopod extension and GV on its surface (black arrowhead), 0 s. An increase in fluorescence intensity is observed over time and the number of neutrophils producing red fluorescence also increases but at variable intensity, b 10 s, and c 20 s. Magnification, $\times 20$

after Ureaplasma sp. [16] to invade the uterine compartment to cause intrauterine infection, reports of this consequence has been limited and indicated variability of disease manifestation. For effective bacterial killing, oxidative burst during phagocytosis is a key element although some pathogens may be evasive. Unlike the robust oxidative burst by both maternal and neonatal PMNL in response to E. coli and GBS, the response to GV was lower and variable in quantity and quality. Whether this is the underlying reason for the variability and scarce reports of symptomatic and invasive GV disease, needs to be studied in further larger clinical trials. Of note, PMNL in the CB from our study showed a higher and less variable oxidative burst response to GV compared to MB. This is contrary to the decreased ROS production in neonatal phagocytes previously reported [17-21]. The proportion of activated PMNL, although not significantly different between $\mathrm{MB}$ and $\mathrm{CB}$, the burst intensity appeared greater in CB. Previous studies have shown significantly higher levels of IgG in CB or neonatal blood compared to maternal circulation with up to two-fold increased $\operatorname{IgG}_{1}$ concentration in $\mathrm{CB}$ at term compared to MB [22-25]. This may explain the increased oxidative burst possibly attributed to greater opsonisation with CB samples. If this is so, it could suggest a passive form of maternal transfer of immunity to the fetus. Further studies are required to measure and compare antibody levels from mothers with GV infection and their newborn outcomes.

Our study showed that the phagocytic killing of GV is likely $\mathrm{HOCl}$-mediated. Reactive oxidants are produced by the phagocyte's NADPH oxidase enzyme, superoxide is then converted to $\mathrm{H}_{2} \mathrm{O}_{2}$, which is catalysed by MPO with chloride, forms $\mathrm{HOCl}$, the most powerful antimicrobial oxidant produced in the phagosome [9]. Using live cell-imaging, we could visualise the oxidative burst production by neutrophils phagocytosing GV (Additional file 1: Movie S1). Phagocytosed pathogens by neutrophils result in an increase in fluorescence, when R19-S reacts with $\mathrm{HOCl}$ to produce the fluorescent R19, in red [13]. Comparing the fluorescence intensity with the previous report at this lab on Staphylococcus aureus, [14] GV appeared to exhibit less fluorescence intensity. The lower intensity may suggest a more modest oxidative burst in the phagocytosis of GV.

In conclusion, our study demonstrated a moderately robust phagocytosis and oxidative burst effect by PMNL on GV. We also showed that PMNL oxidative burst activity was more variable in $\mathrm{MB}$ but more intense in $\mathrm{CB}$, compared to E. coli and GBS. The oxidative killing of GV in PMNL is HOCl-mediated. Future studies are planned to further explore the variability in the host oxidative responses to GV of different strains and the extent of protection from circulating maternal antibodies.

\section{Limitations}

Although uncomplicated in pregnancy, the women's history of previous exposure to GV in particular, were not available. We did not utilise neonatal peripheral blood to obtain PMNL, especially for the live-cell imaging in view of the limited blood sample from a newborn infant that could be drawn to isolate purely neutrophils. Due to limited timing and resources, comparison of live-cell imaging results using GV was only done against the historical findings with Staphylococcus aureus that was recorded at the same facility [14]. 


\section{Abbreviations}

GV: Gardnerella vaginalis; BV: Bacterial vaginosis; ROS: Reactive oxygen species; HOCl: Hypochlorous acid; GBS: Group B Streptococcus; MB: Maternal blood; CB: Cord blood; PMA: Phorbol 12-Myristate 13-Acetate; fMLP: N-formyl-MetLeuPhe; DHR: Dihydrorhodamine; PMNL: Polymorphonuclear leukocyte; MPO: Myeloperoxidase; E. coli: Escherichia coli.

\section{Supplementary Information}

The online version contains supplementary material available at https://doi. org/10.1186/s13104-021-05842-y.

Additional file 1: Movie S1. The phagocytosis of GV by neutrophils and oxidative burst response captured via live-cell imaging fluorescence microscopy over a 24-sec period. Magnification, $\times 20$

\section{Acknowledgements}

We thank the staff for the support provided at the Physiology and Pathology Laboratories, Pre-clinical Sciences Block, Faculty of Medicine, Universiti Kebangsaan Malaysia. We wish to thank Dr. Phon Su Ee from the Department of Obstetrics and Gynaecology for her assistance in obtaining samples for this study. Our heartfelt gratitude to Dr. Amelia M. Albrett and staff of the Centre for Free Radical Research as well as Mr. Trevor Anderson and staff at the Microbiology division, Canterbury Health Laboratories, New Zealand, for their technical expertise and laboratory support. Special thanks to Professors Christine Winterbourn and Anthony Kettle, of the Department of Pathology, University of Otago at Christchurch, for hosting FCC during his sabbatical leave to conduct part of this research project.

\section{Authors' contributions}

AS performed the entire flow cytometry experiments, data analysis and wrote the first draft of the manuscript. NHAA developed and fine-tuned the experiments and contributed in writing of the manuscript. NAA was primarily involved in the acquisition and analyses of the flow cytometry data, adapting and troubleshooting the experimental protocols. KKW was involved in the GV cultures and initial development of the flow cytometry experiments. FCC was the principal investigator, initiated the project and developed the conceptual framework, methodology, involved in the analyses, writing and finalizing of the manuscript. All authors read and approved the final manuscript.

\section{Funding}

This work was funded by Universiti Kebangsaan Malaysia (UKM) to support the sabbatical leave for FCC in 2014 and also with grants from the "Dana Lonjakan Penerbitan (DLP-2011-005), Dana Pembangunan Penyelidikan (DPP-2014-168), Dana Fundamental PPUKM (FF-2015-143)".

\section{Availability of data and materials}

The datasets analysed in this study are available from the corresponding author upon request.

\section{Declarations}

\section{Ethics approval and consent to participate}

This study was approved by the Research Ethics Committee, Universiti Kebangsaan Malaysia. The Declaration of Helsinki's ethical rules were strictly observed and all procedures were performed according to the relevant regulations and guidelines. Informed written consent was obtained from the participants in this study.

\section{Consent for publication}

Not applicable.

\section{Competing interests}

The authors declare that they have no competing interests.

\section{Author details}

${ }^{1}$ Department of Paediatrics, Faculty of Medicine, Universiti Kebangsaan Malaysia, Jalan Yaacob Latif, 56000 Kuala Lumpur, Malaysia. ${ }^{2}$ Department of Obstetrics and Gynaecology, Faculty of Medicine, Universiti Kebangsaan Malaysia, Kuala Lumpur, Malaysia. ${ }^{3}$ Department of Pathology, Faculty of Medicine, Universiti Kebangsaan Malaysia, Kuala Lumpur, Malaysia. ${ }^{4}$ Department of Medical Microbiology and Immunology, Faculty of Medicine, Universiti Kebangsaan Malaysia, Kuala Lumpur, Malaysia.

Received: 16 July 2021 Accepted: 10 November 2021 Published online: 22 November 2021

\section{References}

1. Turovskiy Y, Sutyak Noll K, Chikindas ML. The aetiology of bacterial vaginosis. J Appl Microbiol. 2011;110(5):1105-28.

2. Sharma D, Shastri S, Farahbakhsh N, Sharma P. Intrauterine growth restriction-part 1. J Matern Fetal Neonatal Med. 2016;29(24):3977-87.

3. Svare J, Schmidt H, Hansen B, Lose G. Bacterial vaginosis in a cohort of Danish pregnant women: prevalence and relationship with preterm delivery, low birthweight and perinatal infections. BJOG Int J Obstet Gynaecol. 2006;113(12):1419-25.

4. Bertran T, Brachet P, Vareille-Delarbre M, Falenta J, Dosgilbert A, Vasson $\mathrm{M}-\mathrm{P}$, et al. Slight pro-inflammatory immunomodulation properties of dendritic cells by Gardnerella vaginalis: the "Invisible Man" of bacterial vaginosis? J Immunol Res. 2016;2016:9747480.

5. Patterson JL, Stull-Lane A, Girerd PH, Jefferson KK. Analysis of adherence, biofilm formation and cytotoxicity suggests a greater virulence potential of Gardnerella vaginalis relative to other bacterial-vaginosis-associated anaerobes. Microbiology. 2010;156(Pt 2):392.

6. Roselletti E, Sabbatini S, Perito S, Mencacci A, Vecchiarelli A, Monari C. Apoptosis of vaginal epithelial cells in clinical samples from women with diagnosed bacterial vaginosis. Sci Rep. 2020;10(1):1-9.

7. Gomez-Lopez N, Romero R, Garcia-Flores V, Xu Y, Leng Y, Alhousseini A, et al. Amniotic fluid neutrophils can phagocytize bacteria: a mechanism for microbial killing in the amniotic cavity. Am J Reprod Immunol. 2017;78(4):e12723.

8. Green JN, Winterbourn CC, Hampton MB. Analysis of neutrophil bactericidal activity. Methods Mol Biol. 2007:412:319-32.

9. Hampton MB, Kettle AJ, Winterbourn CC. Inside the neutrophil phagosome: oxidants, myeloperoxidase, and bacterial killing. Blood J Am Soc Hematol. 1998;92(9):3007-17.

10. Winterbourn CC, Hampton MB, Livesey JH, Kettle AJ. Modeling the reactions of superoxide and myeloperoxidase in the neutrophil phagosome implications for microbial killing. J Biol Chem. 2006;281(52):39860-9.

11. Hampton MB, Vissers MC, Winterbourn CC. A single assay for measuring the rates of phagocytosis and bacterial killing by neutrophils. J Leukoc Biol. 1994;55(2):147-52.

12. Segal AW, Dorling J, Coade S. Kinetics of fusion of the cytoplasmic granules with phagocytic vacuoles in human polymorphonuclear leukocytes. Biochemical and morphological studies. J Cell Biol. 1980;85(1):42-59.

13. Chen X, Lee K-A, Ha E-M, Lee KM, Seo YY, Choi HK, et al. A specific and sensitive method for detection of hypochlorous acid for the imaging of microbe-induced $\mathrm{HOCl}$ production. Chem Commun. 2011;47(15):4373-5.

14. Albrett AM, Ashby LV, Dickerhof N, Kettle AJ, Winterbourn CC. Heterogeneity of hypochlorous acid production in individual neutrophil phagosomes revealed by a rhodamine-based probe. J Biol Chem. 2018;293(40):15715-24.

15. Easmon C, Clark L, Crane J, Green R. Phagocytosis and killing of Gardnerella vaginalis by human neutrophils. J Clin Pathol. 1985;38(7):747-9.

16. Hillier SL, Martius J, Krohn M, Kiviat N, Holmes KK, Eschenbach DA. A casecontrol study of chorioamnionic infection and histologic chorioamnionitis in prematurity. N Engl J Med. 1988;319(15):972-8.

17. Destin KG, Linden JR, Laforce-Nesbitt SS, Bliss JM. Oxidative burst and phagocytosis of neonatal neutrophils confronting Candida albicans and Candida parapsilosis. Early Human Dev. 2009;85(8):531-5.

18. Moriguchi N, Yamamoto S, Isokawa S, Andou A, Miyata H. Granulocyte functions and changes in ability with age in newborns; report no. 1: flow cytometric analysis of granulocyte functions in whole blood. Pediatr Int. 2006;48(1):17-21.

19. Polin RA, St-Geme J 3rd. Neonatal sepsis. Adv Pediatr Infect Dis. 1992;7:25-61. 
20. Wolach B, Sonnenschein D, Gavrieli R, Chomsky O, Pomeranz A, Yuli I. Neonatal neutrophil inflammatory responses: parallel studies of light scattering, cell polarization, chemotaxis, superoxide release, and bactericidal activity. Am J Hematol. 1998;58(1):8-15.

21. Yamazaki M, Matsuoka T, Yasui K, Komiyama A, Akabane T. Increased production of superoxide anion by neonatal polymorphonuclear leukocytes stimulated with a chemotactic peptide. Am J Hematol. 1988;27(3):169-73.

22. Coe CL, Lubach GR, Izard KM. Progressive improvement in the transfer of maternal antibody across the order primates. Am J Primatol. 1994;32(1):51-5.

23. Fridén BE, Makiya R, Nilsson BM, Holm S, Stigbrand TI. The human placental immunoglobulin $\mathrm{G}$ receptor and immunoglobulin $\mathrm{G}$ transport. Am J Obstet Gynecol. 1994;171(1):258-63.
24. Malek A, Sager R, Kuhn P, Nicolaides KH, Schneider H. Evolution of maternofetal transport of immunoglobulins during human pregnancy. Am J Reprod Immunol. 1996;36(5):248-55.

25. Malek A, Sager R, Schneider H. Maternal-fetal transport of immunoglobulin $\mathrm{G}$ and its subclasses during the third trimester of human pregnancy. Am J Reprod Immunol. 1994;32(1):8-14.

\section{Publisher's Note}

Springer Nature remains neutral with regard to jurisdictional claims in published maps and institutional affiliations.
Ready to submit your research? Choose BMC and benefit from:

- fast, convenient online submission

- thorough peer review by experienced researchers in your field

- rapid publication on acceptance

- support for research data, including large and complex data types

- gold Open Access which fosters wider collaboration and increased citations

- maximum visibility for your research: over $100 \mathrm{M}$ website views per year

At BMC, research is always in progress.

Learn more biomedcentral.com/submissions 